\title{
Assessment of differential brachial plexus block using ropivacaine in intraoperative conscious patients: A randomized control trial
}

\author{
Anitha Nileshwar ${ }^{1}$, Karthik Chandra Babu ${ }^{2}$, Abhishek Rao Kordcal ${ }^{3 *}$, Anil K Bhat ${ }^{4}$ \\ Professor Anaesthesiology ${ }^{1}$, Junior Resident Anaesthesiology ${ }^{2}$, Assistant Professor Anaesthesiology ${ }^{3 *}$, \\ Professor, Orthopaedic Surgery, Kasturba Medical College, Manipal University, Manipal, India.
}

\begin{abstract}
Background: During orthopaedic surgical procedures such as trigger finger repair or tendon repair, differential nerve block (DNB) can permit intraoperative assessment of adequacy of surgery. The current study was undertaken to compare the efficacy and safety of $0.15 \%$ ropivacaine and $0.1285 \%$ ropivacaine in producing DNB for hand surgeries.
\end{abstract}

Methods: This was a randomized controlled trial of 40 participants, aged 18-60 years, either gender, ASA I/II requiring hand or forearm surgery. Participants were randomized to receive $25 \mathrm{ml}$ of either $0.15 \%$ (Group R15) or $0.1285 \%$ ropivacaine (Group R1285). Onset of sensory and motor block, requirement of additional analgesia or general anaesthesia for surgery was noted.

Results: DNB was achieved in 18/20 (90\%) patients in Group R15 and in 10/20 (50\%) patients in Group R1285 ( $\mathrm{P}=0.057)$. In group $\mathrm{R} 15$, mean time to achieve DNB was $15.26 \pm 3.5$ minutes and it was12.78 \pm 5.6 minutes in $\mathrm{R} 1285$ group $(\mathrm{P}=0.165)$. Mean duration of DNB was $15.52 \pm 3.7$ minutes among R15 and $18.89 \pm 3.3$ minutes among R1285 $(\mathrm{P}=0.027)$. Duration of surgery was 20 minutes in both groups. Two patients $(10 \%)$ in each group developed full motor block and $8(40 \%)$ patients among R1285 needed general anaesthesia.

Conclusion: Differential block sufficient to permit surgery of short duration is possible with both concentrations but success rate is higher with $0.15 \%$ ropivacaine.

Keywords: Brachial plexus block; differential nerve block; hand surgery; regional anaesthesia; ropivacaine

\section{Introduction}

Supraclavicular brachial plexus block is one of the commonly used anaesthetic techniques for a wide variety of hand and forearm surgeries. ${ }^{1}$ Brachial plexus block produces excellent sensory and motor block, however, causes interference with intra and postoperative functional assessment and delayed recovery of motor function in the postoperative period.

Differential nerve blockade (DNB) with adequate sensory block allows performance of pain free surgery with preservation of sufficient motor power.
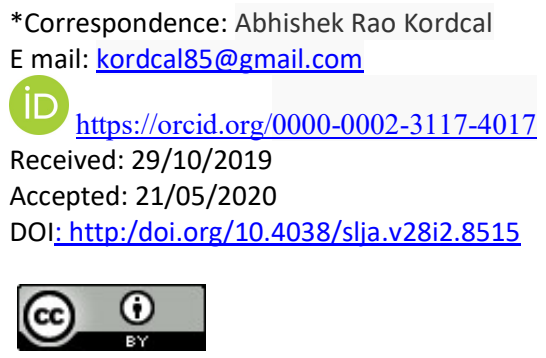

During certain orthopaedic procedures such as tendon transfer or tendon repairs and trigger finger release, DNB may be more desirable as this allows the surgeon to assess the adequacy of surgery intraoperatively. Even though there were early animal models and clinical studies documenting differential nerve blockade ${ }^{2,3}$, only one study till date had attempted it in brachial plexus block on patients undergoing forearm and hand surgery which recommended $0.1285 \%$ concentration ropivacaine for producing differential nerve block. ${ }^{4}$

There is no published literature till date, on orthopedic procedures performed with differential nerve block as well as intraoperative assessment of motor function in an awake or responsive patient. Thus, the study aimed to compare the efficacy and safety of $0.15 \%$ ropivacaine and $0.1285 \%$ ropivacaine to produce differential nerve block for hand surgeries. The primary objective was success rate of producing 
differential nerve block. The secondary objectives were to compare patient satisfaction, requirement of supplementary sedation, safety and conversion to general anesthesia.

\section{Materials and methods}

This prospective, randomized control trial was conducted between December 2016 to June 2018. Approval was obtained from institutional ethical committee of Kasturba Hospital, Manipal. The trial registered with clinicaltrials.gov. Patients aged between 18 and 60 years, American Society of Anaesthesiologists Physical Status (ASA PS) 1 and 2, scheduled for hand or forearm surgery using supraclavicular brachial plexus block with sensory analgesia alone and not requiring motor block were included. Patients who were not willing to be awake during surgery, with known difficult airway and known allergy to ropivacaine were excluded from the study.

The patients were visited the day before surgery and once enrolled and willing, a written informed consent was taken from the patient. Standard fasting instructions were given. All patients were premedicated with oral alprazolam $0.5 \mathrm{mg}[>50 \mathrm{~kg}]$ and $0.25 \mathrm{mg}[<50 \mathrm{~kg}]$. Ranitidine $150 \mathrm{mg}$ was given orally if patient had a history of acid peptic disease. Any medication being taken by the patient was continued or discontinued according to standard guidelines. On the day of surgery, the fasting status was confirmed. The patient was shifted to the operating room and monitoring 5 electrode ECG, pulse oximetry and non-invasive blood pressure (NIBP)] commenced. Intravenous access was secured in the upper limb contralateral to the surgical site.

The patients were randomly allocated using computer-generated random number sequence into one of two groups - Group R12 receiving $25 \mathrm{ml}$ of $0.15 \%$ ropivacaine $(19 \mathrm{ml}$ of $0.2 \%$ ropivacaine with $6 \mathrm{ml}$ of isotonic saline) and Group R15 receiving $25 \mathrm{ml}$ of $0.1285 \%$ ropivacaine (16 $\mathrm{ml}$ of $0.2 \%$ ropivacaine with 9 $\mathrm{ml}$ of isotonic saline). Allocation concealment was done by Serially Numbered Opaque Sealed Envelope (SNOSE) method. All patients were blinded to the group assignment. There were three observers in the study.
Observer 1 (Anaesthesia Consultant) loaded the drugs and performed supraclavicular brachial plexus block, after receiving the allocation sequence from the independent statistician.

Observer 2 (Anaesthesia Resident), who was blinded to the group assigned, serially assessed the patients after administration of the block.

Observer 3 (Consultant Orthopaedic Surgeon), blinded to the group allocation of the patient and performed all surgeries as well as assessed the adequacy of differential nerve block.

The patient was positioned supine, with a $45^{\circ}$ head up. Supraclavicular brachial plexus was visualized on the side to be operated on, using an ultrasound linear 3-8 $\mathrm{MHz}$ probe (Logiq E, from GE). A $5 \mathrm{~cm}$ long block needle was inserted using an 'in plane' technique after local anaesthetic skin wheal was raised. $10 \mathrm{ml}$ of the local anaesthetic solution was injected, first at the corner pocket (beneath the brachial plexus, lateral to the subclavian artery and above the first rib), another $10 \mathrm{ml}$ above the plexus but within the sheath and $5 \mathrm{ml}$ within the plexus, taking care that there was no undue resistance or pain to injection of the drug. A tourniquet was applied in the upper arm on the side to be operated. $10 \mathrm{ml}$ of $2 \%$ lignocaine with adrenaline was used to raise a subcutaneous wheal of local anesthetic along the medial side of the upper arm above the level of tourniquet to ensure blockade of intercostobrachial nerve.

Characteristics of the block was assessed every five minutes for 30 minutes and then every 30 minutes thereafter till surgery was complete. The sensory block was evaluated using pinprick test at little finger (ulnar nerve), thenar eminence (median nerve), dorsum of the hand over the metacarpophalangeal joint (radial nerve), and the lateral external side of the forearm (musculocutaneous nerve). Motor function was evaluated by thumb abduction (radial nerve), thumb opposition (median nerve), thumb adduction (ulnar nerve), and flexion of the elbow (musculocutaneous nerve). The grading is mentioned in Table 1. 
Table 1: Sensory and motor blockade grading

Sensory blockade was graded as follows:

$0=$ Anaesthesia or complete loss of touch sensation

$1=$ Analgesia or loss of sharp sensation and pain

$2=$ Reduced sensitivity compared with the same

territory on the contralateral side at each area

$3=$ Normal sensation.

The grading of motor power was done as follows:

5 - Hold test position against maximum resistance,

4 - Hold test position against moderate resistance,

3 - Hold test position against gravity,

2 - Able to move through full range of movement gravity eliminated

1 - No palpable or observable muscle contraction.

The sensory block is defined as reduced skin sensitivity compared with the same territory on the contralateral side at each area. Successful sensory block was defined as sensory block $\leq 1$, maintenance of motor function as MMT $\geq 3$. And differential block as sensory block $\leq 1$ and $\mathrm{MMT} \geq 3$ during surgery.

Sample size was calculated assuming successful block $\%$ as the primary outcome variable which was $40.90 \%$ in a study by Kii $\mathrm{N}$ et $\mathrm{al}^{4}{ }^{4}$ Assuming $40 \%$ difference between the two groups, as clinically significant difference, with $80 \%$ power and $5 \%$ one sided alpha error, the sample size was calculated to be 18 in each group. To allow for a loss to follow up of about $10 \%$, it was decided to randomize 20 subjects to each group. Sample size calculation was conducted using STATA statistical software version IC 13.5

\section{Statistical analysis}

Data analysis was done by Intention to Treat (ITT) analysis. Mean values of normally distributed quantitative variables were compared using independent sample t-test. Median values of non-normally distributed quantitative variables were compared using Mann-Whitney $\mathrm{U}$ test. Categorical variables were compared using Chi-square test/ Fisher's exact test. P value $<0.05$ was considered as statistically significant. IBM SPSS statistical software version 21 was used for data analysis. ${ }^{6}$

\section{Results}

Both the study groups were comparable with respect to age, gender distribution, weight, height ASA grading and mean duration of surgery $(\mathrm{P}$ value $=0.295)($ Table2 $)$. The type of surgeries performed were varied as mentioned in Table 3.

Table 2: Patient characteristics

\begin{tabular}{|c|c|c|c|}
\hline \multirow[b]{2}{*}{ Parameter } & \multicolumn{2}{|l|}{ Group } & \multirow[b]{2}{*}{ P value } \\
\hline & $\begin{array}{l}\text { Group R15 } \\
(\mathbf{N}=\mathbf{2 0})\end{array}$ & $\begin{array}{l}\text { Group } \\
\text { R1285 } \\
(\mathbf{N}=20)\end{array}$ & \\
\hline Age & $46.45 \pm 12.47$ & $\begin{array}{l}47.4 \pm \\
10.79 \\
\end{array}$ & 0.798 \\
\hline \multicolumn{4}{|l|}{ Gender } \\
\hline Male & $10(50 \%)$ & $10(50 \%)$ & \multirow{2}{*}{1.00} \\
\hline Female & $10(50 \%)$ & $10(50 \%)$ & \\
\hline Weight (kg) & $57.45 \pm 9.91$ & $\begin{array}{l}61.25 \pm \\
10.23\end{array}$ & 0.240 \\
\hline Height (cm) & $163.4 \pm 8.08$ & $\begin{array}{l}158.55 \pm \\
7.88 \\
\end{array}$ & 0.062 \\
\hline \multicolumn{4}{|l|}{ ASA } \\
\hline I & $11(55 \%)$ & $14(70 \%)$ & \multirow{2}{*}{0.327} \\
\hline II & $9(45 \%)$ & $6(30 \%)$ & \\
\hline $\begin{array}{l}\text { Surgery } \\
\text { duration (min) }\end{array}$ & $22 \pm 16.09$ & $\begin{array}{l}17.75 \pm \\
7.86\end{array}$ & 0.295 \\
\hline
\end{tabular}

Table 3: Comparison of surgical procedures performed between two groups $(\mathrm{N}=40)$

\begin{tabular}{|l|c|c|}
\hline \multirow{2}{*}{ Surgery } & \multicolumn{2}{|c|}{ Group } \\
\cline { 2 - 3 } & $\begin{array}{c}\text { Group R15 } \\
\text { (N=20) }\end{array}$ & $\begin{array}{c}\text { Group R1285 } \\
\text { (N=20) }\end{array}$ \\
\hline $\begin{array}{l}\text { Endoscopic carpal tunnel } \\
\text { release }\end{array}$ & $8(40 \%)$ & $6(30 \%)$ \\
\hline De Quervain's disease & $2(10 \%)$ & $4(20 \%)$ \\
\hline Tendon repair & $5(25 \%)$ & $2(10 \%)$ \\
\hline Trigger finger & $5(25 \%)$ & $2(10 \%)$ \\
\hline 4 TH MTP joint arthrolysis & $0(0 \%)$ & $1(5 \%)$ \\
\hline Dupuytren's contracture & $0(0 \%)$ & $1(5 \%)$ \\
\hline $\begin{array}{l}\text { Extensor compartment } \\
\text { release }\end{array}$ & $0(0 \%)$ & $1(5 \%)$ \\
\hline Guyon's canal release & $0(0 \%)$ & $1(5 \%)$ \\
\hline $\begin{array}{l}\text { R middle finger corrective } \\
\text { osteotomy }\end{array}$ & $0(0 \%)$ & $1(5 \%)$ \\
\hline Radial tunnel syndrome & $0(0 \%)$ & $1(5 \%)$ \\
\hline
\end{tabular}

*No statistical test was applied- due to 0 subjects in the cells

The proportion of people achieving a successful differential block was higher in R15 group, as compared to R1285 group ( $90 \%$ in R15 vs $50 \%$ in $\mathrm{R} 1285, \mathrm{P}$ value $<0.001)$. The median patient satisfaction score in group R15 was 2 (IQR 0 to 
2) and 2 (IQR 2 to 6 ) in group R12 which was statistically significant difference $(\mathrm{p}=0.021)$. The difference in the proportion of rescue analgesia between two groups was statistically significant (R15:6 (30\%), R1285: 14 (70\%)) ( $\mathrm{p}=0.011)$. None of the subjects in R15 group needed conversion to general anaesthesia, but $8(40 \%)$ subjects in R12 group required conversion to GA (Table 4).

Table 4: Comparison of success and characteristics of differential block

\begin{tabular}{|c|c|c|c|}
\hline \multirow[b]{2}{*}{ Parameter } & \multicolumn{2}{|l|}{ Group } & \multirow[b]{2}{*}{ P-value } \\
\hline & $\begin{array}{l}\text { Group R15 } \\
(\mathrm{N}=\mathbf{2 0})\end{array}$ & $\begin{array}{l}\text { Group } \\
\text { R1285 } \\
(\mathrm{N}=20)\end{array}$ & \\
\hline $\begin{array}{l}\text { Successful } \\
\text { differential block }\end{array}$ & $18(90 \%)$ & $10(50 \%)$ & $\mathbf{0 . 0 1 3 8}^{*}$ \\
\hline $\begin{array}{l}\text { Time to } \\
\text { differential block } \\
(\mathrm{min})\end{array}$ & $20 \pm 3.73$ & $19 \pm 4.59$ & $0.531^{\#}$ \\
\hline $\begin{array}{l}\text { Block to incision } \\
\text { (min) }\end{array}$ & $20 \pm 3.24$ & $19.5 \pm 3.2$ & $0.627^{\#}$ \\
\hline \multicolumn{4}{|c|}{ Duration of differential block (min) } \\
\hline 5 & $4(22.22 \%)$ & $2(20 \%)$ & \multirow{5}{*}{ ND } \\
\hline 10 & $10(55.55 \%)$ & $6(60 \%)$ & \\
\hline 15 & $1(5.555 \%)$ & $2(20 \%)$ & \\
\hline 20 & $2(11.11 \%)$ & $0(0 \%)$ & \\
\hline 45 & $1(5.555 \%)$ & $0(0 \%)$ & \\
\hline $\begin{array}{l}\text { Patient satisfaction } \\
\text { median (IQR) }\end{array}$ & $2(0,2)$ & $2(2,6)$ & $0.021^{\wedge}$ \\
\hline \multicolumn{4}{|c|}{ Need for rescue analgesia and complications } \\
\hline Rescue analgesia & $6(30 \%)$ & $14(70 \%)$ & 0.011 \\
\hline Conversion to GA & $0(0 \%)$ & $8(40 \%)$ & * \\
\hline Sedation required & $6(30 \%)$ & $11(55 \%)$ & 0.110 \\
\hline Tourniquet pain & $0(0 \%)$ & $0(0 \%)$ & $*$ \\
\hline $\begin{array}{l}\text { Any other } \\
\text { complications }\end{array}$ & $0(0 \%)$ & $0(0 \%)$ & $*$ \\
\hline
\end{tabular}

*Fisher's exact test, \# Independent sample t-test, $\wedge$ Mann-Whitney U test, ND= Not done

\section{Discussion}

Peripheral nerve block such as brachial plexus block has become a popular technique in extremity surgery. It is beneficial if the patient remains awake and actively moves in response to the surgeon's commands. Utilization of an ultrasound-guided nerve block technique facilitates faster and more accurate conduct of nerve block with less complications. ${ }^{7}$ Lower concentration of ropivacaine has already been shown to produce differential block when used for labour analgesia. ${ }^{8}$ It is believed that the $\mathrm{C}$ fibers are more susceptible than larger fibers but many other factors such as length and diameter of the nerve, myelination and distribution of sodium and potassium channels also affect the quality of the block. Use of a tourniquet to achieve a bloodless field is a common local practice for these surgeries. For this reason, ultrasound guided supraclavicular brachial plexus block was given in all these patients. Since low concentrations of ropivacaine were being used, the volume of drug injected was kept high at $25 \mathrm{ml}$.

In the study conducted by Kii et $\mathrm{al}^{4}$, axillary nerve block was given with varying concentrations of ropivacaine along with GA for hand or forearm soft tissue surgery. The results showed $16 \mathrm{ml}$ of $0.1285 \%$ ropivacaine was suitable for achieving differential block. Although differential block could not inhibit every nerve input, they showed that postoperative pain and satisfaction scores were acceptable in most patients. ${ }^{1}$ The minimum concentration that provided effective analgesia in $95 \%$ of the patients was $0.148 \%$ and the highest concentration at which motor function may be maintained was $0.15 \%$. In view of these findings, the present study was designed to compare $0.1285 \%$ and $0.15 \%$ ropivacaine. The higher concentration was chosen because unlike in the Kii et al study, patients in this study had to be awake during the surgery and possibly required a greater intensity of sensory block.

Gonzalez-Suarez $\mathrm{S}$ et al showed that the time to onset of sensory block was 10-20 min and 1535 min for motor block or sufficient surgical analgesia with 150-200 $\mathrm{mg}$ of ropivacaine for axillary brachial plexus block. Motor block was delayed to $30-60$ min with the use of dilute solutions of ropivacaine (both 0.1285 and $0.15 \%$ ) in the present study. However, the sensory block lasted up to 9-11 h. ${ }^{9}$ Janzen et al reported that the duration of the sensory block induced by high-dose ropivacaine (636 min) did not significantly differ from the duration of the 
motor block it induced (642 min), and that these durations were not suitable for day stay upperlimb surgery. ${ }^{10}$ Freitag et al studied axillary brachial plexus block with varying volumes of ropivacaine $(0.75 \%-10 \mathrm{ml}, 20 \mathrm{ml}$ and $40 \mathrm{ml})$ and found that a higher dose of ropivacaine prolonged the duration of block. ${ }^{11}$ A higher dose is expected to produce a more potent blockade. ${ }^{9}$ 10

Increasing ropivacaine concentration leads to a weaker grip, which could compromise patient satisfaction. ${ }^{11}$ Prolonged or excessive motor block is not appropriate for soft-tissue surgery with a short operation time or day surgery, because motor block sometimes causes selfcaring disability and delays discharge. ${ }^{12}$ In the present study, onset of sensory block took 15-20 min and motor block needed 35-45 min. Thus, sensory block was always obtained first and was followed by motor block.

In the present study block was administered for different surgical procedures. In trigger finger release, the absence of triggering can be checked intraoperatively after the release. Post-tendon repair, the surgeon would assess the adequacy of repair, gaping at suture site and tendon excursion. In Dupuytren's contracture release, endoscopic carpal tunnel release, to know the potential damage to tendon after release. In metacarpophalangeal joint arthrolysis, the range of movement achieved and in corrective osteotomy, the adequacy of malunion correction and rotational alignment. It is said that differential nerve block is more useful for procedures such as trigger finger release and tendon repairs rather than carpal tunnel release. Soft-tissue surgery is performed around the hand or forearm using delicate surgical techniques. Fasciectomy presents a risk of neurological complications and postoperative inflammation or swelling may lead to neural compression. ${ }^{13}$

Future studies must be designed to prolong the duration of differential nerve block. The surgery needs to be quick and differential nerve block will not be available if the surgeon needs to revise his surgery in the same sitting after the initial assessment. Such prolongation may be possible by using more dilute concentration of ropivacaine but with additives that provide analgesia but do not produce motor block.

\section{Conclusion}

Study showed that it is feasible to produce differential block sufficient to permit surgery of short duration $(<30 \quad \mathrm{~min})$ with both concentrations. However, patients who receive $0.1285 \%$ ropivacaine are more likely to require sedation, analgesia and even conversion to general anaesthesia. On the other hand, motor blockade is more likely with $0.15 \%$ ropivacaine after about 30 minutes.

Acknowledgements We acknowledge the technical support in data entry and analysis by Evidencian Research Associates, Bangalore.

\section{References}

1. Nowakowski P, Bieryło A. Ultrasound guided axillary brachial plexus plexus block. Part 1-basic sonoanatomy. Anaesthesiol Intensive Ther. 2015;47(4):409-16.

https://doi.org/10.5603/AIT.2015.0052

PMid:26401746

2. Ford DJ, Raj PP, Singh P, et al. Differential peripheral nerve block by local anesthetics in the cat. Anesthesiol. 1984;60(1):28-33.

https://doi.org/10.1097/00000542-198401000$\underline{00007}$

PMid:6691593

3. Gissen AJ, Covino BG, Gregus J. Differential sensitivities of mammalian nerve fibers to local anesthetic agents. Anesthesiol. 1980;53(6):46774.

https://doi.org/10.1097/00000542-198012000$\underline{00006}$

PMid:7457962

4. Kii N, Yamauchi M, Takahashi K, et al. Differential axillary nerve block for hand or forearm soft-tissue surgery. J Anesth. 2014;28(4):549-53.

https://doi.org/10.1007/s00540-013-1773-7 PMid:24375222

5. StataCorp. 2013. Stata Statistical Software: Release 13. College Station, TX: StataCorp LP.

6. Honnannavar KA, Mudakanagoudar MS. Comparison between Conventional and Ultrasound-Guided Supraclavicular Brachial Plexus Block in Upper Limb Surgeries. Anesth EssaysRes.2017;11(2):467-71.

https://doi.org/10.4103/aer.AER $43 \_17$ PMid:28663643 PMCid:PMC5490112

7. Wilson MJ, MacArthur C, Cooper GM, et al. Ambulation in labour and delivery mode: a randomised controlled trial of high-dose vs mobile epidural analgesia. Anaesthesia. 2009; 64(3):266-72.

https://doi.org/10.1111/j.13652044.2008.05756.x

PMid:19302638

8. González-Suárez S, Pacheco M, Roigé J, et al. Comparative study of ropivacaine $0.5 \%$ and levobupivacaine $0.33 \%$ in axillary brachial plexus block. Reg Anesth Pain Med. 
2009;34(5):414-9.

https://doi.org/10.1097/AAP.0b013e3181ae729b PMid:19920417

9. Janzen PR, Vipond AJ, Bush DJ, et al. A comparison of $1 \%$ prilocaine with $0.5 \%$ ropivacaine for outpatient-based surgery under axillary brachial plexus block. Anesth Analg. 2001;93(1):187-91.

https://doi.org/10.1097/00000539-20010700000037

PMid:11429363

10. Freitag M, Zbieranek K, Gottschalk A, et al. Comparative study of different concentrations of prilocaine and ropivacaine for intraoperative axillary brachial plexus block. Eur J Anaesthesiol.2006;23(6):481-6.

https://doi.org/10.1017/S0265021506000263

PMid:16507196
11. Vainionpää VA, Haavisto ET, Huha TM, et al. A clinical and pharmacokinetic comparison of ropivacaine and bupivacaine in axillary plexus block. Anesth Analg. 1995;81(3):534-8. https://doi.org/10.1213/00000539-19950900000019

12. Fredrickson MJ, Smith KR, Wong AC. Importance of volume and concentration for ropivacaine interscalene block in preventing recovery room pain and minimizing motor block after shoulder surgery. Anesthesiol. 2010;112(6):1374-81

https://doi.org/10.1097/ALN.0b013e3181d6929d PMid:20460999 